\title{
Levels of Abstraction in Maritime Maneuvering Operations
}

Johannes Petersen

Center for Human-Machine Interaction, Oersted *DTU, Automation, Technical University of Denmark, DK-2800 Kongens Lyngby, Phone: +45 45253579, Fax: +45 45881295, jop@oersted.dtu.dk

\section{INTRODUCTION}

An important part of maritime operations is to control the movements of the vessel - often referred to as maneuvering. In restricted waters and harbor areas the autopilot is often switched off and the crew has to perform the maneuvering of the vessel manually by controlling the forces produced by control devices (or actuators) such as rudder, main propeller, and thrusters. The increasing size of vessels and traffic-intensity has led to increasing demands on the crew's ability to maneuver vessels in a safe and efficient manner.

The maneuvering of large container carriers is a dynamic control task requiring on-line decision-making about appropriate interventions. This chapter describes different levels of means-end abstraction of the maritime work domain that are relevant for maneuvering tasks. It is argued that information systems supporting the decision-making processes of the navigating crew should provide alternative interpretations of maneuvering situations corresponding to the proposed means-end abstraction levels.

The original version of this chapter was revised: The copyright line was incorrect. This has been corrected. The Erratum to this chapter is available at DOI: 10.1007/978-0-387-35611-2_22 


\section{THE MARITIME WORK DOMAIN}

When designing information systems supporting human decision-making in complex work settings it is important to come to terms with the substance matter of the work domain.

Rasmussen (1986), has proposed the so-called abstraction hierarchy as a framework for representing complex work domains. The abstraction hierarchy is based on different levels of means-end abstraction, spanning the gap between physical form and the overall purposes and constraints imposed by the environment. Bottom-up the hierarchy describes which components and functions may serve higher levels purposes, and top-down it describes how purposes can be implemented by functions and components.

According to Rasmussen (1991) the representation of a work domain is supposed constitute the space of possibilities from which the actualities are selected in a particular situation. This is similar to a city map representing the possible routes between different locations, from which an actor can make decisions about an actual route from A to B (Vicente, 1999).

The different levels of abstraction of the maritime work domain, which we have found to be important for maneuvering tasks, are given in Table 1 (see also (Petersen and Nielsen, 2001)).

Table 1. Relevant means-end abstraction levels of the maritime work domain.

\begin{tabular}{|l|l|}
\hline Levels & Content \\
\hline Purpose & The position and heading of the vessel \\
\hline Vessel Movements & $\begin{array}{l}\text { The movements of the vessel (longitudinal and } \\
\text { transverse velocity, and turn-rate) }\end{array}$ \\
\hline Force Exertion & $\begin{array}{l}\text { Controllable and uncontrollable forces acting on the } \\
\text { vessel }\end{array}$ \\
\hline Force Production & $\begin{array}{l}\text { Force production of the rudder, main propeller, thrusters, } \\
\text { tugs, hawsers, anchors (control devices), wind and } \\
\text { current (disturbances) }\end{array}$ \\
\hline Physical Form & Appearance and location of physical entities \\
\hline
\end{tabular}

The upper-most level in Table 1 (Purpose) describes the overall purpose of maneuvering a vessel. The purpose is given in terms of position and heading of the vessel. These may be constrained by traffic, obstacles (quay, buoys etc.) and legal barriers such as traffic separation schemes and the rules of the road. The next lower level (Vessel Movements) is concerned with vessel movements in different dimensions, constrained by e.g. fuel saving strategies and legal speed limits. The next lower level (Force Exertion) is concerned with the forces acting on the vessel causing changes in its state of motion. One level down (Force Production) the focus is on the role of the 
different entities producing forces on the vessel. This includes not only ordinary control devices such as rudder, main propeller, thrusters and tugs, but also disturbances such as wind and current which are in fact occasionally used as constructive means of force production. Finally, at the bottom level of abstraction (Physical Form) we have a description of the appearance and location of physical entities.

It is important to note that the means-end abstraction levels in Table 1 capture only the substance matter of the work domain relevant for maneuvering tasks and not navigational tasks. While maneuvering has to do with short-term changes of vessel position and heading (reflected at the upper-most level of means-end abstraction in Table 1) navigation typically refers to the long-term planning involved in conducting a vessel from $A$ to B. Navigation will not be discussed further in this chapter.

\section{DECISION-MAKING}

In view of the different means-end abstraction levels in Table 1, the construction of successful maneuvering operations can be understood as a matching between the consequences of force production (propagating upwards in the means-end hierarchy) and the overall purposes and constraints of the maneuvering task (propagating downwards in the meansend hierarchy). Due to the many-to-many relations among the levels the need for decision-making arises.

For instance, when a certain force interaction, which is supposed to bring about an intended vessel movement, is required the typical thing to do is to change the balance between controllable and uncontrollable forces acting on the vessel, by changing the intensity of the controllable force being produced. However, in case it is not possible to bring about the desired movements of the vessel using the control devices an alternative might be to inhibit the uncontrollable forces acting on the vessel or even modify the intended state of vessel motion.

Although forces stemming from wind and current are considered uncontrollable such forces are actually functions of the area of the vessel being exposed to these disturbances - the area above the water line and the area below the water line, respectively. This means, that such forces can be inhibited by changing the orientation of the vessel (although in many cases this implies that the actual goal is abandoned).

Even though overall goals of a specific maneuvering task are always issued top-down, given as desired position and heading at the upper-most level of abstraction, ultimately, the concrete objectives have to be derived bottom-up, in view of the actual possibilities of force production offered by 
the control devices in the particular situation (see (Lind, 1999) for more details on the distinction between goals and objectives).

In this chapter I hope to have demonstrated the relevance of work domain analysis for the design of information systems supporting the decision-making processes of the navigating crew on large container carriers when performing maneuvering tasks. An important conclusion is that such information systems should enable alternative interpretations of maneuvering situations, corresponding to the different means-end abstraction levels of the maritime work domain proposed in Table 1.

\section{REFERENCES}

Lind, M. (1999). Plant modelling for supervisory control. Trans. Inst. MC, Vol. 21. No. 4/5, pp. 171-180.

Petersen, J. \& Nielsen, M. (2001). Analyzing Maritime Work Domains. Proc. of Cognitive Science Approaches to Process Control (CSAPC), Munich, Germany, Sept. 2001, Onken, R. (Ed.).

Rasmussen, J. (1986). Information Processing and Human-Machine Interaction. An Approach to Cognitive Engineering, Amsterdam: North-Holland.

Rasmussen, J. (1991). Modelling Distributed Decision Making. In: Rasmussen, J., Brehmer, B. and Leplat, J (Eds.). Distributed Decision Making: Cognitive Models for Cooperative Work. John Wiley \& Sons, Inc., New York.

Vicente, K.J. (1999). Cognitive Work Analysis: Toward Safe, Productive, and Healthy Computer-Based Work. Lawrence Erlbaum Associates, Publishers, Mahwah. 